\title{
EXPERIENCE IN NORSK HYDRO WITH CUBIC EQUATIONS OF STATE
}

\author{
SIGURD SKOGESTAD
}

Norsk Hydro, Research Centre, N3901 Porsgrunn, Norway

\begin{abstract}
The paper presents some specific applications of cubic equations of state (EOS) in Norsk Hydro and points out some aspects of such equations that one should be aware of when using them or when developing new equations. Is is emphasized that the use of EOS to calculate vapor-liquid equilibrium is inherently empirical. Activity coefficients predicted for some systems by the Soave-Redlich-Kwong (SRK) equation of state are presented. The limitations of the van Laar equation for activity coefficients which may be derived from SRK at infinite pressures does not necessarily apply at finite pressures. The shortcomings of the SRK equations of state are pointed out and suggestions are given on how to develop an extended SRK-equation.
\end{abstract}

\section{INTRODUCTION}

Cubic equations of state like the SRK equation are widely used by chemical engineers for VLE calculations. They have replaced Raoults law as the "first try" methud. This is due to their simplicity combined with a remarkable accuracy. Compared to activity coefficient based methods, equations of state have the great advantage that there are no special problems with supercritical components. Furthermore the number of parameters is much less - for SRK only $T_{c}, P_{c}$ and one other parameter (which may be obtained from $T_{b}$ ) for each component. By adding ideal gas enthalpy data for each pure component the engineer has virtually all the data needed for process simulations (VLE, enthalpy, entropy, densities). For mixtures there is only one parameter for each binary which may often be set equal to 0 .

In Norsk Hydro the SRK equation has been used for many different systems. It started more than eight years ago with oil and gas processing calculations at high pressures close to the critical point. More recent applications include crude oil refining, separation of air, $\mathrm{H}_{2}-\mathrm{N}_{2}-\mathrm{Ar}_{-}-\mathrm{CH}_{4}$, ammonia-water, chlorinated hydrocarbons with $\mathrm{HCl}$, air-water and water-hydrocarbons.

The SRK equation is used throughout this paper. However, most of the arguments presented are equally valid for other forms of cubic EOS.

0378-3812/83/\$03.00 으 1983 Elsevier Science Publishers B.V. 
VLE BY EQUATIONS OF STATE : INHERENTLY FMPIRICAL.

l anking rloser at how an equation of state (EOS) works for VLE calculations, the greatest surprise is that it works at all. An EOS represents volumetric (pVT) properties. Fig. 1 shows how both liquid and vapor volumes may be reproduced with a single cubic EOS. The equation is analytical and gives a smooth transition from liquid to vapor volumes through the two phase region. This is of course not according to nature which is non-analytical at the bubble and dew pointe. However, for calculating single phase volumetric properties it does not matter which volumes are predicted inside the two phase region. We could say that the two-phase region is "free to use", and what is in fact done when applying equations of state to VLE is to use this region to "store" the vapor pressures. This is completely empirical and is obtained by forcing the volumetric behaviour inside the two-phase region to obey Maxwells equal-area rule (Fiy. 2). Maxwells rule cumes from the criterion of equal fugacities in both phases for a pure component at VLE.

It should be stressed that equilibrium conditions cannot be derived from volumetric properties alone. Even with a "perfect" equation of state which accurately reproduced liquid and vapor volumes, we would not necessarily get correct vapor pressures. For VLE calculations the hypothetical volumetric properties inside the two phase region are in fact the most important, and this part of the rurve should be established hy using vapor pressure data (or other thermodynamic data like enthalpy and entropy).

An interesting point about applying equations of state to VLE is that it does not matter for the VLE calculations what vapor and liquid volumes we get. However, it is of course most convienient if the same equation may be used to calculate volumetric propertics as well.

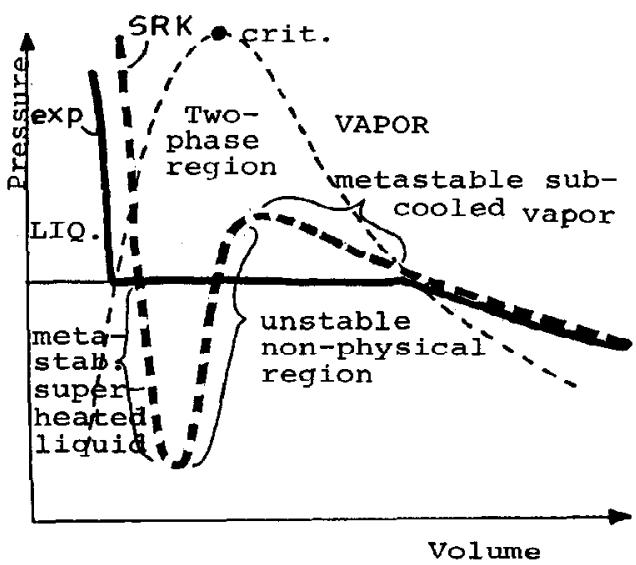

FIG 1. Typical isotherms for a pure component

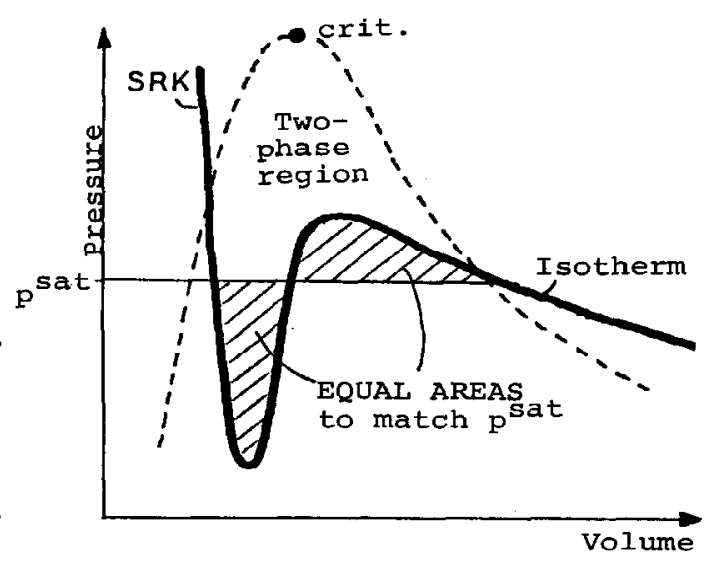

FIG.2 Calc. of $p^{\text {sat }}$ for a pure comp. 
THE SRK EQUATION

Soave used the Redlich-Kwong equation of state for the vapor phase as a starting point

$$
P=R T / V-b-a / V(V+b)
$$

The first term is a combination of the ideal gas term $(\rho \rightarrow R T / V$ when $V \rightarrow \infty)$ and the repulsive term $(p \rightarrow \infty$ when $V \rightarrow b)$. The second term is the attractive term which pulls down the pressure and makes the van der Waals loop. Soave fitted this equation to experimental vapor pressure by making the a-parameter temperature dependent

$$
a=a_{c}(1+m(1-\sqrt{T / T}))^{2}
$$

This approach gives quite accurate vapor volumes and vapor pressures and hence the heat of vaporization will be reasonable as well. From an engineering point of view this is important because the heat of vaporization often is the most important part of an enthalpy balance.

Matching $T_{c}$ and $P_{c}$. The SRK equation has four parameters for each pure component ( $a_{c}$, $\left.m, T_{c}, b\right)$, but this number is reduced to three $\left(T_{c}, P_{c}, m\right)$ by using the following two constraints:

1) $\left(T_{C}, P_{c}\right)$ is un the vapor pressure curve

2) $\left(T_{c}, P_{c}\right)$ is the last point on the vapor pressure curve.

This gives

$$
\begin{aligned}
& \mathrm{a}_{\mathrm{c}}=0.42747 \mathrm{R}^{2} \mathrm{~T}_{\mathrm{c}}^{2} / \mathrm{P}_{\mathrm{c}} \\
& \mathrm{b}=0.08664 \mathrm{RT}_{\mathrm{c}} / \mathrm{P}_{\mathrm{c}}
\end{aligned}
$$

Some typical values for a and b (+ the "solubility" parameter $\delta$ ) are presented in Table 1.

The second constraints is equivalent to setting $Z_{c}=0.33$ for all pure components. This is too high in most cases. The fact that SRK usually gives too high liquid volumes is closely related to this constraint. This was realized by Peng and Robinson who modified the RK equation to give $Z_{c}=0.307$. This improved the liquid densities somewhat for most pure components, but the values are still not good enough for engineering calculations. The VLE calculations are hardly affected at all and the Peng-Robinson equation therefore does not represent any real improvement compared to SRK from a practical point of view. In fact, it mostly creates problems, because the engineer is faced with two instead of one equation to use. 


\begin{tabular}{lccc}
\hline & $a\left(\mathrm{Jm}^{3} / \mathrm{mol}^{2}\right)$ & $b\left(\mathrm{~cm}^{3} / \mathrm{mol}\right)$ & $\delta=\sqrt{\ln 2 \mathrm{a} / \mathrm{b}^{2}}\left(\left(\mathrm{cal} / \mathrm{cm}^{3}\right) l / 2\right)$ \\
$\mathrm{H}_{2}$ & 0.010 & 18.2 & 2.46 \\
$\mathrm{CH}_{4}$ & 0.189 & 29.6 & 6.55 \\
$\mathrm{nC}_{4}$ & 1.878 & 80.7 & 7.57 \\
$\mathrm{nC}_{6}$ & 3.916 & 120.5 & 7.32 \\
$\mathrm{nC}_{10}$ & 10.610 & 212.2 & 6.84 \\
$\mathrm{C}_{6} \mathrm{H}_{6}$ & 2.933 & 82.3 & 9.28 \\
$\mathrm{H}_{2} \mathrm{O}$ & 0.990 & 21.1 & 21.21 \\
$\mathrm{EtOH}_{\mathrm{tOH}}$ & 2.361 & 58.3 & 11.75 \\
$\mathrm{NH}$ & 0.574 & 25.9 & 13.04 \\
\hline
\end{tabular}

TABLE I Typical pure component SRK parameters at $273.15 \mathrm{~K}$.

Vapor pressures. The m-parameter in the SRK equation may be estimated from the acentric factor $\omega$ (e.g. with Soave's correlation $m=0.480+1.574 \omega-0.176 \omega^{2}$ ), but should preferably be fitted to pure component vapor pressures in the temperature range of interest. It is often convenient to use the normal boiling point to obtain $\mathrm{m}$. In cases where high accuracy is needed (e.g. for separation of close-boiling components) and for some polar substances (e.g. water) the temperature dependence of the a-parameter suggested by Soave is not adequate. This may be solved in most cases by adding an extra parameter to make the $\mathrm{m}$-factor a linear function of temperature.

Liquid and critical region. If we match $T_{c}$ and $P_{c}$ using the two constraints above and fit in to vapor pressure data, the only way to get satisfactory volumetric properties in the liquid and critical region as well is to add more pure component parameters. At least two parameters are probably needed to match both regions. Péneloux (1982) has introduced one extra parameter in an elegant way: A linear translation, $c$, along the volume axis will not affect the vapor pressure ( see Fig. 2). The modified SRK equation becomes

$$
P=R T /(V+c-b)-a(T) /(V+c)(V+c+b))
$$

Péneloux has shown that the VLE calculations for mixtures is not affected by the translation provided a simple molar average mixing rule for $c$ is used. The new parameter c may be used to match densities in the liquid or critical regions. For engineering applications it is probably most important to improve SRK's ability to predict the critical region, as the separate correlations which are used for liquid densities work all right in most cases. Vapor phase densities will hardly be changed at all by introducing $c$.

Vapor reqion. The RK equation gives good vapor densities and enthalpies for nonpolar components, but for polar components like water and ammonia, errors may be significant. This is especially the case with enthalpy departures where derivatives of volume with respect to temperature are involved. An example: When saturated ammonia at 16 bor $/ 40^{\circ} \mathrm{C}$ is expanded adiabatically to 1 bar the final temperature should be about $-2^{\circ} \mathrm{C}$. SRK gives $12^{\circ} \mathrm{C}$ bcoause SRK predicts the gas to be more ideal than it actually is. 
SRK applied to mixtures. The main reason for the widespread use of the SRK is the good results usually found for multicomponent VLE. The following simple mixing rules which were suggested by Redlich and Kwong (1949) work very well in most cases :

$$
\begin{aligned}
& a=\underset{i j}{\sum \sum} x_{i} x_{j} a_{i j}=a_{1} \times 2+a_{2} \times 2+\ldots .+2 a_{12} \times 1 \times 2+\ldots \\
& a_{i j}=\sqrt{a_{1} a_{j}}\left(1-k_{i j}\right) \\
& b=\sum x_{i} b_{i}
\end{aligned}
$$

Excellent results may be obtained for a lot of industrially important mixtures (hydrocarbons) wlthout using any binary perameter $k_{i j}$ Other systems (e.g. hydrocarbons + light gases such as $\mathrm{H}_{2} \mathrm{~S}, \mathrm{CO}_{2}$ and $\mathrm{N}_{2}$ ) may be handled by using one interaction parameter for each binary. Mixtures with supercritical components are very common in industrial applications. These create problems when using an activity coefficient based model for VLE calculations as one has to extrapolate $f_{i}^{\text {set }}$ (pure liquid fugacity) beyond $T_{c}$ or start using other reference states than the pure component. Supercritical components present no problem when using an EOS.

\section{ACTIVITY COEFFICIENTS PREDICTED BY SRK}

Equations of state are increasingly being used for VLE calculations instead of activity coefficient based methods. This shift will continue in the next years to come as improved and more flexible equations of state are developed. Although activity coefficient are not used directly in the equation of state approach, they may be calculated for comparison.

Vidal (1978) derived for SRK the expression for the activity coefficients in the liquid phase when $\mathrm{p}+\infty$. For a binary mixture this becomes

$$
\begin{aligned}
R \operatorname{RIm}_{1} & =b_{1} \Phi_{2}^{2}\left(\left(\delta_{1}-\delta_{2}\right)^{2}+2 k_{1} \delta_{1} \delta_{2}\right) \\
\Phi_{i} & =\text { volume fraction } i=b_{i} x_{i} / \Sigma b_{j} x_{j} \\
\delta_{i} & =\text { "solubility parameter" }=\sqrt{\ln 2 a_{i} / b_{i}^{2}}
\end{aligned}
$$

Eqn.(9) is a one-parameter form of van Laars expression for $\gamma$ and it is equivalent to the equation Hildebrand and Scatchard developed from regular solution theory (Reid et.al, 1977). The equation is not valid for polar components.

No simple relation for $\gamma$ may be found from SRK for finite pressures (Vidal, 1978). The validity of (9) at finite pressures may be checked by calculating $\gamma$ with 5RK for a mixture at fixed pressure. For a component in the liquid phase the following applies

$$
r_{\mathrm{i}}=\hat{\varphi}_{\mathrm{i}} / \varphi \operatorname{Lt}^{0}
$$




\begin{tabular}{|c|c|c|c|c|c|c|}
\hline \multirow[b]{2}{*}{ (1) (2) } & \multirow[b]{2}{*}{$k_{i j}$} & \multirow[b]{2}{*}{$p$ (bar) } & \multicolumn{2}{|c|}{$\begin{array}{l}\text { Calculated with } \\
\text { SRK (eqn. 12) at } \\
\text { finite pressure }\end{array}$} & \multicolumn{2}{|c|}{$\begin{array}{l}\text { Calculated from } \\
p=\infty \text { (eqn. 9) with } \\
\text { data from Table } 1\end{array}$} \\
\hline & & & $\gamma_{1}$ & $r_{2}$ & $\Upsilon_{1}$ & $\gamma_{2}$ \\
\hline $\begin{array}{l}\mathrm{CH}_{4}-\mathrm{nCl}^{0} \\
\mathrm{nC} 4-\mathrm{nC}_{6} \\
\mathrm{nC} 6-\mathrm{C} 6 \mathrm{H} 6 \\
\mathrm{nC4}-\mathrm{H}_{2} \mathrm{O} \\
\mathrm{EtOH}-\mathrm{H}_{2} \mathrm{O} \\
\mathrm{NH}_{3}-\mathrm{H}_{2} \mathrm{O} \\
\mathrm{NH}_{3}-\mathrm{H}_{2} \mathrm{O}\end{array}$ & $\begin{array}{l}0.0 \\
0.0 \\
0.0 \\
0.0 \\
0.0 \\
0.0 \\
-0.28\end{array}$ & $\begin{array}{l}104.8 \\
0.535 \\
0.054 \\
1.139 \\
0.021 \\
3.668 \\
1.256\end{array}$ & $\begin{array}{l}1.999 \\
1.002 \\
1.094 \\
2.063 \\
1.509 \\
1.716 \\
0.605\end{array}$ & $\begin{array}{c}1.054 \\
1.001 \\
1.142 \\
28.085 \\
4.253 \\
2.395 \\
0.584\end{array}$ & $\begin{array}{l}1.031 \\
1.003 \\
1.124 \\
2.689 \\
1.759 \\
1.706 \\
0.493\end{array}$ & $\begin{array}{c}1.004 \\
1.002 \\
1.186 \\
43.982 \\
4.764 \\
1.926 \\
0.420\end{array}$ \\
\hline
\end{tabular}

TABLE 2 Activity coefficient for equimolar liquid mixtures at $273.15 \mathrm{~K}$

The fugacity coefficient $\hat{\varphi}_{i}^{L}$ comes as a direct result of a calculation with SRK for the mixture at the given $T$ and $p . \varphi_{i}^{L D}$ is the fugacity coefficient of the component as pure liquid (which might be hypothetical) at the same $T$ and $p$ and is obtained from SRK with a separate calculation for each pure component.

Activity coefficients obtained at finite pressure and at $p=\infty$ (eqn. 9) are shown in Table 2. The agreement is quite good, but there does not seem to be any general relation between the activity coefficients obtained at finite and at infinite pressures. It should be pointed out that the limitations of eqn. 9 do not necessarily apply at finite pressures. This is illustrated by Figure 7 which shows activity coefficients in ammonia-water mixtures predicted with SRK using $k_{i j}=-0.28$. The minimum in the activity coefficient for water cannot be abtained with a van Laar type of equation. This implies that SRK may be capable of handling a broader range of mixtures than expected from the eqn. 9 which is derived for SRK at $p=\infty$.

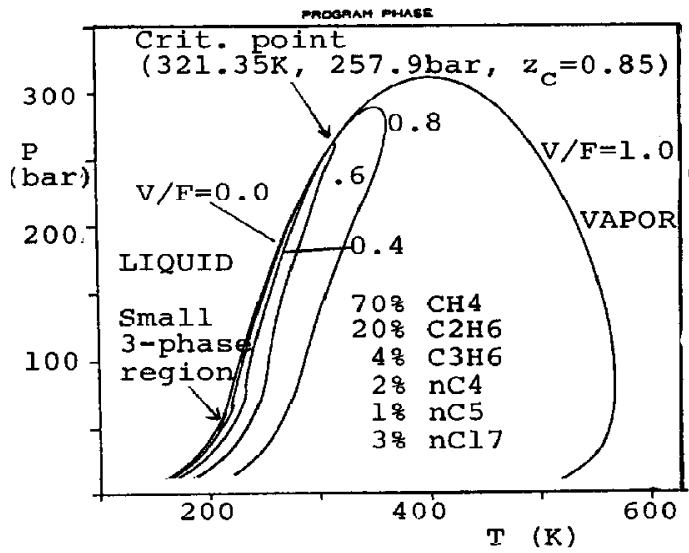

FIG. 3 Lines of constant vapor fraction predicted by SRK for natural gas mixture

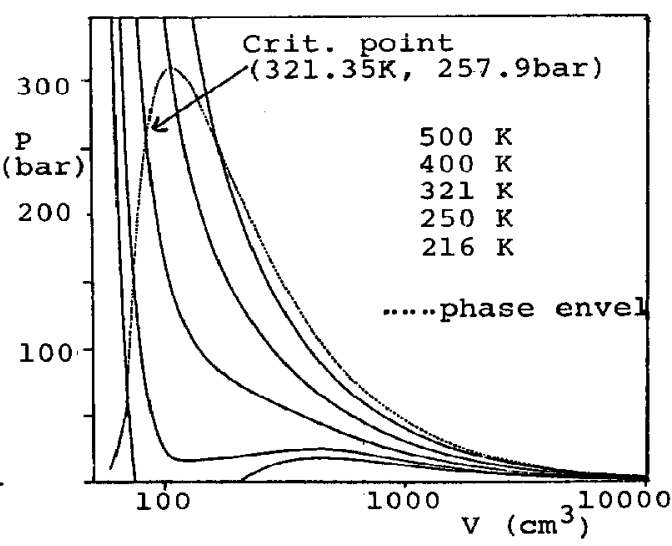

FIG. 4 lsotherms predicted by SRK for natural gas mixture. 


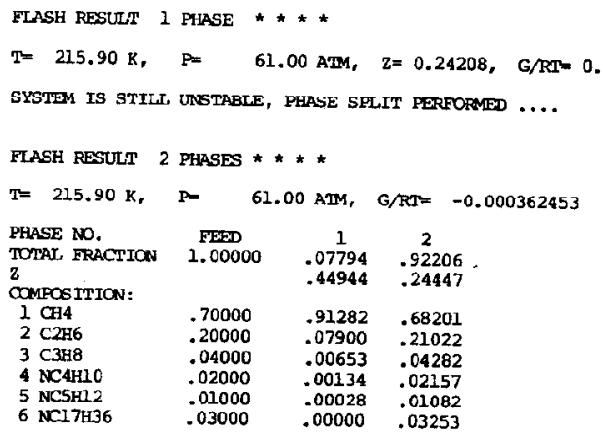

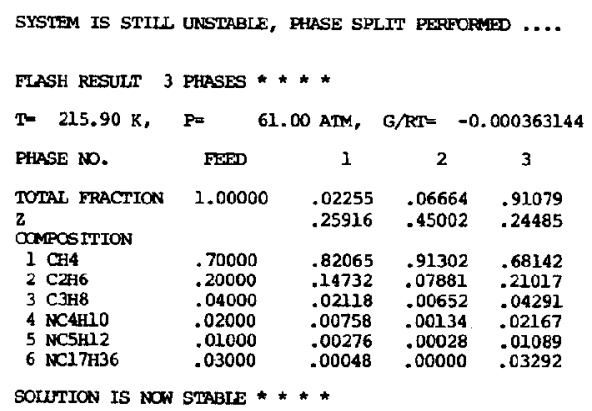

FIG. 5 Computer output of three phase flash calculations (SRK) with program FLASH3

\section{SOME APPLICATIONS OF SRK}

\section{Natural Gas Mixture}

Figs. 3 and 4 show phase envelope and isotherms predicted by SRK for a typical natural gas mixture with all $k_{i j}=0$. The isotherms of $F i g .4$ are typical for mixtures; it is only at lower temperatures that we get isotherms with 3 mathematical volume roots in the two phase region (only one of these is a physical solution). SRK predicts $z_{c}=0.85$ for the mixture, ie. the constraint $z_{c}=0.33$ is valid only for pure components. The critical isotherm of a mixture does not have a point of inflection at the critical point (Fig. 4). Another aspect worth mentioning is that in the dew point region around max $T$, the compressibility factor ( $_{\mathrm{liq}}$ ) of the liquid in equilibrium with the vapor, is greater than zap. This may seem to be incorrect, but the liquid phase is in fact heavier due to its greater mole weight. (Example: The dew point at $495 \mathrm{~K}, 257.8$ bar: $\mathrm{z}_{\text {vap }}=1.03, \mathrm{z}_{11 \mathrm{q}}=1.14$, $\left.M W_{\text {vap }}=28.1, M W_{l i q}=64, \rho_{\text {vap }}=170.6 \mathrm{~kg} / \mathrm{m}^{3}, \rho_{\text {liq }}=351.3 \mathrm{~kg} / \mathrm{m}^{3}\right)$.

Another interesting aspect with this system (at least from an academic point of view) is that SRK predicts a very small three-phase region (VLLE) nearby the critical point of methane. Computer output of the three-phase calculation is shown in Fig. 5 . It should be emphasized that this is a predicted three-phase reglon not necessarlly found in practice. It illustrates that SRK is capable of predicting liquid-liquid equilibria even for simple hydrocarbon systems. By adding some water to this system, SRK predicts four phases; the fourth phase being almost pure liquid water (in practice this would of course be ice). The phase envelope and multiphase calculations were performed with the powerful computer programs TERM and FLASH3 developed by M. Michelsen (1980, 1982a, 1982b). The FLASH3 program handles up to four coexisting phases and is capable of doing flash calculations closer than $0.01 K$ to the critical point. This demonstrates the numerical robustness of the flash algorithms developed by Michelsen. 


\section{Water-hydrocarbons}

With an interaction parameter between hydrocarbons and water of approx. 0.5 , SRK will accurately predict the three phase split and compositions of the vapor and hydrocarbon liquid phase. However, the solubility of hydrocarbons in the water phase will often be several orders of magnitude too low. For most engineering applications this error will not be important. The reason for the error is that the original SRK mixing rule does not apply at all for this system. Moshfegian (1979) has solved the problem by introducing a separate set of interaction parameters $k_{i j}{ }^{2}$ for the water phase (which means that $k_{i j}$ is made composition dependent). By making this parameter temperature dependent they get accurate results also for the composition of the water rich phase. For the methane-water system $k_{i j}{ }^{2}$ is approx. -0.30 at $35^{\circ} \mathrm{C}$ and 0.0 at $150^{\circ} \mathrm{C}$.

\section{HCI-VCM-EDC}

The enthalpy and VLE behavior of the system $\mathrm{HCl}$ - VCM(chloroethylene) EDC(1,2-dichloroethane) may also be accurately predicted with the SRK equation. In industrial conditions $\mathrm{HCl}$ and $\mathrm{VCM}$ will be present in the liquid at temperatures up to $200^{\circ} \mathrm{C}$. This is well above $\mathrm{T}_{\mathrm{c}}$ of both $\mathrm{HCl}$ and VCM. We have fitted binary parameters for SRK based on experimental VLE data (Table 4). Comparisons with plant data show very good agreement.

\section{Ammonia-Water}

SRK gives reasonably good results for the ammonia-water system. Knapp (1982) has suggested an interaction parameter of -0.28 which we have adopted. The agreement with literature date (Macriss, 1964) is quite good (see Fig. 6). However, in the region of high ammonia concentrations at pressures greater than about 1 bar the predicted volatility of water is far too low (Table 3). The fact that the pressure (and not the temperature) seems to create the problem suggests that there is something wrong with the vapor phase model. The possibility of significant association of water and ammonia in the vapor phase has been suggested by Gillespie and Wilson (1982) in an unpublished report.

\begin{tabular}{cccc}
\hline $\begin{array}{c}\text { Pressure } \\
\text { (psia) }\end{array}$ & $\begin{array}{c}\text { yH2O (ppm) reported } \\
\text { by Macriss (1964) }\end{array}$ & \multicolumn{2}{c}{ Predicted SRK } \\
& & $y_{H}$ (pPm) & T (K) \\
6 & 1.1 & 1.3 & 226.0 \\
10 & 2.0 & 2.5 & 235.1 \\
20 & 7.4 & 6.5 & 248.9 \\
30 & 16.5 & 11.5 & 257.8 \\
40 & 30.0 & 17.4 & 264.7 \\
60 & 70.0 & 31.3 & 275.1 \\
\hline
\end{tabular}

TABLE 3. Ammonia-water. Vapor phase composition of 90 wt $\%$ ammonia mixture 
The activity coefficients predicted from SRK (Fig. 7) seem reasonable compared to published data (eg. Edwards, 1978). The agreement with the unpublished results of Gillespie and $W$ ilson (1982) is in fact very good. They also predict the minimum in $\gamma_{\mathrm{H} 2 \mathrm{O}}$ at low concentrations of water. The predicted $\gamma_{\mathrm{H} 2 \mathrm{O}}^{\infty}$ at higher temperatures (373.15 K) is probably too high, but apart from this SRK is doing an impressive job for the activity coefficients of this system using only one temperature independent binary parameter. This is probably more due too good fortune than to the general capability of the SRK equation for these kinds of systems. The temperature dependence of the activity coefficients is related to the heat of mixing. The heat of mixing predicted with SRK for an equinolar mixture is $-3.4 \mathrm{~kJ} / \mathrm{mol}$ in the range from $273.15 \mathrm{~K}$ to $323.15 \mathrm{~K}$. This compares quite well with the value of about $-4.4 \mathrm{~kJ} / \mathrm{mol}$ reported by Macriss (1964).

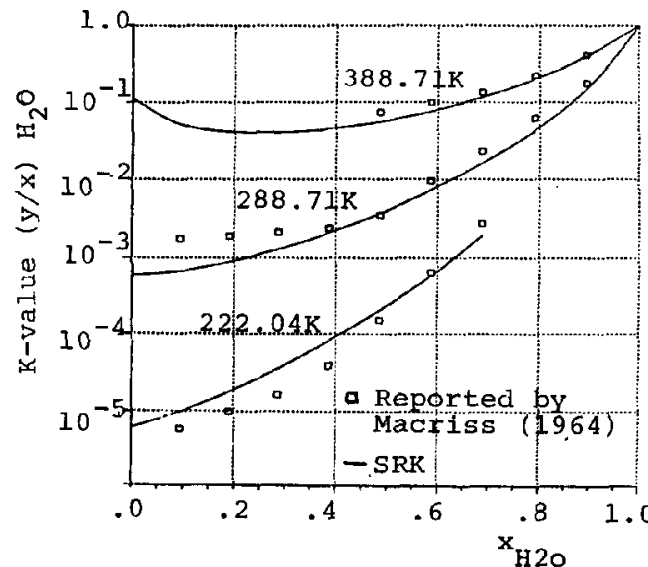

FlG. 6 Ammonia-water. K-value water

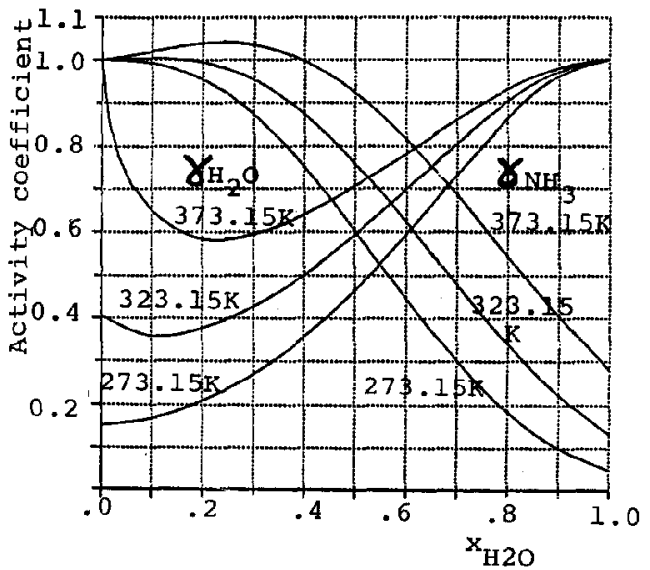

FIG. 7 Ammonie-water. Activity coefficients predicted by SRK

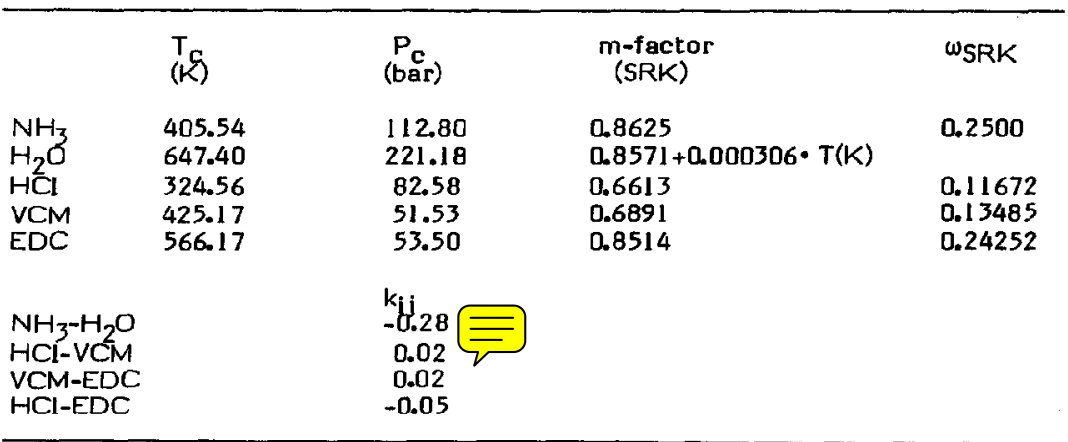

TABLE 4. Parameter values used with the SRK equation. 


\section{FUTURE NEEDS FOR CUBIC EQUATIONS OF STATE}

The Soave equation of state has several shortcomings that are well recognized. Firstly, its ability to predict pure component properties is not good enough (liquid and critical densities, polar components in general). This may be solved by adding more pure component parameters to make the equation more flexible. However, one of the main advantages about SRK is its simplicity. The new parameters should therefore only be used in special cases and the equation should reduce to the original SRK equation when the new parameters are set equal to 0 . Secondly, the mixing rules are not adequate. These should be generalized by introducing density dependent mixing rules and more parameters (Mollerup, 1981). Here as well it is important that the mixing rules reduce to the original RK mixing rules when the new binary parameters are set equal to 0 .

As VLE calculations by EOS are inherently empirical, the decision about which type of equation and which kind of mixing rule to choose should be based on extensive testing with experimental VLE data.

From a practical (industrial) point of view it would be very convenient (but probably quite unrealistic) if one could agree upon using one equation of state (eg. an extended SRK equation) and stick to this for the next years to come. This would mean that parameters presented in literature could be implemented immediately by the industry and thus save a lot of duplication of effort.

\section{REFERENCES}

Edwards, T.J., J.Newman and J.M.Prausnitz, 1978, Thermodynamics of Vapor-Liquid Equilibria for the Ammonia-Water System, Ind. Eng. Chem. Fundam., 17, 4, 264

Gillesple, P.C. and G.M.Wilson, 1982, Unpublished UIPPR Report, Project 805

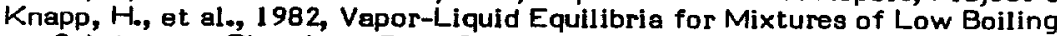
Substances, Chemistry Data Series, Vol. VI, DECHEMA, Frankfurt

Macriss, R.A. et al., 1964, Physical and Thermodynamic Properties of Ammonia-Water Mixtures, Institute of Gas Technology, Chicago, $\mathbf{n l .}$

Michelsen, M.L., I 980, Calculation of Phase Envelopes and Critical Points for Multicomponent Mixtures, Fluid Phase Equilibria, 4, 1-10

Micheisen, M.L., 1982a, The Isothermal Flash Problem Part I : Stability Analysis, Fluid Phase Equilibria, 9, 1-19

Michelsen, M.L., 1982b, Part II : Phase Split Calculations, ibid, 21-40

Mollerup, J., 1981, A note on Excess Gibbs Energy Models, Equations of State and the Local Composition Consept, Fluid Phase Equilibria, 7, 121

Moshfeghian, M., A. Shariat and J.H.Erbar, 1979, Application of the PFGC-MES Equation of State to Synthetic and Natural Gas Systems, ACS Symp. Ser. 133

Péneloux, A. and E.Rauzy, 1982, A Consistent Correction For Redlich-Kwong- Soave Volumes, Fluid Phase Equilibria, 8, 7

Reid, R.C., J.M. Prausnitz and T.K.Sherwood, 1977, The Properties of Gases and Liquids, 3rd. ed., McGraw-Hill Book Co., New York, pp. 326

Soave, G., 1972, Equilibrium constants from a modified Redlich-Kwong equation of state, Chem. Eng. Sci., 27, 1197

Vidal, J., 1978, Mixing Rules and Excess Properties in Cubic Equations of State, Chem. Eng. Sci., 33, 787 